\title{
STRUCTURAL CHANGES IN SECTORAL EMPLOYMENT
}

\author{
Iv. Stoycheva* \\ Department of Economics, Faculty of Economics, Trakia University, Stara Zagora, Bulgaria
}

\begin{abstract}
Structural changes in employment, that are a result from the specific influence of structure determining factors are viewed as changes with time in the proportions of the economic system. The opportunities for the development of one or another sector or region are the result of favourable changes in the structures. At the same time, the formation of objective conditions for favourable economic structural changes is an effective tool for the economic development of a certain sector, which provides more appropriate adjustment of economic structures to the requirements of time.

This study aims at exploring structural changes in employment by sector (according to the Classification of the Economic Activities of Bulgaria-2008) through integrated and aggregated measures. The registering of these changes makes tracking the trends in economic development, the intensity of the changes and the unevenness in the distribution of resources between sectors possible. On this basis, there can be drawn guidelines to improve the distribution in the sectoral employment, by setting out priority actions for increasing the efficiency of the use of labour resources.
\end{abstract}

Key words: structural changes; integrated coefficient; intensity of structural changes; economic development.

\section{INTRODUCTION}

All employees by economic sectors and activities play a key role in the growth and prosperity of the economy, ensuring social stability, higher living standards and prosperity, for sustainable economic growth. The structure of employment determines the overall structure of the economy and to a large extent is changing under the influence of its dynamics. Some of the regional economic problems are associated with the searching of options for the reorganization and redirection of labour resources in order to build a structure corresponding to a more advanced in its development economics. In this regard, the implementation of an effective regional policy should be linked to changes in the sectoral structure of employees and their shifting to sectors and industries with higher productivity. Countries with a weaker economy have different economic conditions and resource

\footnotetext{
*Correspondence to: Ivanka Stoycheva, Department of Economics, Faculty of Economics, Trakia University, Stara Zagora, Bulgaria, e-mail:vania_jekova@abv.bg, phone:+35942699430
}

security in comparison with developed countries. This involves determining the sectors and industries in which they have comparative advantages and focusing their resources to economic activities that are more efficient and provide competitive advantages. That brings an opportunity for the allocation of resources to priority sectors and economic activities, and is a prerequisite for achieving higher productivity and economic growth.

This study aims to monitor the intensity of structural changes in employment by key sectors and to make a comparative assessment of the impact of these changes and to measure the diversity of dynamics in terms of the strength of structural changes. The research is based on structural employment by economic sectors through monitoring the intensity of structural changes over time. The sectors considered in accordance with the Classification of Economic Activities-2008 (CEA-2008) and the years selected for comparative assessment are 2000, 2007 and 2016. 


\section{MATERIALS AND METHODS}

Structural changes for the separate years are studied by the relative shares of employment in each district to the employees during the surveyed year throughout the country. These structural shares are calculated in individual sectors too, as it is specified the proportion of those employed in the sector from a given area related to the total number of employees in the sector. The methods for the measurement and analysis of structural changes have been developed by K. Gatev, N. Yankova, V. Grigorova, V. Ryabcev, Salai, etc. In the current research the interest is focused on integrated coefficients that characterize both the absolute and relative changes in their interdependence. The comparison of aggregated coefficients in one period to those of another, gives information on the intensity of structural changes over time. To characterize the structural changes in employment according to the Classification of the Economic Activities of Bulgaria-2008
STOYCHEVA IV.

there are applied two aggregated measurements:

$\checkmark$ that of K. Gatev, following the formula (1):

$$
K s=\sqrt{\frac{\sum\left(W i_{1}-W i_{0}\right)^{2}}{\sum W i_{0}{ }^{2}+\sum W i_{1}{ }^{2}}}
$$

The index of structural changes proposed by V. Ryabtsev, which does not overstate the structural changes and this makes it a preferred (2):

$$
K s r=\sqrt{\frac{\sum\left(W i_{1}-W i_{0}\right)^{2}}{\sum\left(W i_{1}+W i_{0}\right)^{2}}}
$$

These integrated coefficients are scaled within the range between zero and one as the coefficient of Ryabtsev is a smaller quantity than that of Gatev. The following Scale is applied for the standardization and interpretation of the coefficients of structural changes (2).

Scale for the standardization and interpretation of the coefficients of structural changes

\begin{tabular}{|l|l|}
\hline Meaning of the coefficient & Economic interpretation \\
\hline 0,00 & No structural changes have occurred \\
\hline from 0.01 to 0.05 & Very weak and low structural changes \\
\hline from 0.06 to 0.10 & Weak structural changes \\
\hline from 0.11 to 0.20 & Moderate structural changes \\
\hline from 0.2 to 0.40 & Significant structural changes \\
\hline from 0.41 to 0.60 & Strong structural changes \\
\hline from 0.61 to 0.99 & $\begin{array}{l}\text { Very strong, intensive structural } \\
\text { changes }\end{array}$ \\
\hline 1,00 & structural changes \\
\hline
\end{tabular}

\section{RESULTS AND DISCUSSION}

One of the ways to study structural changes in employment and its changes with time is based on the relative change of the participation of employees in the various sectors and branches of the economy. The intensity of the relative change is connected with the level of development of the regions and the country as a whole and the opportunities for the economic system to achieve effective economic growth corresponds with its ability to adapt to changing conditions. In the analysis of sectoral differences the fact that the sectors in an economy are interrelated and form a complete system should be taken into account. In this sense, the relative increase or decrease of employees in one sector would inevitably affect the connected parts in this system. The calculated relative values in Table 1 show that in 2000 , the largest proportion $(24.1 \%)$ is of the employed in the sector, "Agriculture, forestry and fishing", while in 2007 and 2016, most are employed in the sector of "Trade, transport, hotel and restaurant management "and their relative share amounts respectively to $23.2 \%$ and $25.6 \%$ compared with all employed in the country.

The comparison of 2007 to 2000 shows a significant reduction in employment in the primary sector, which is 4.7 percentage points or the pace of growth is minus $19.4 \%$. In 2016 , 
compared to 2000 , the change in the share of employment in this sector is estimated at minus 6 percentage points and the percentage of this reduction is minus $25.1 \%$. Reduction of the relative participation of employees in comparison with 2000 is obvious in the sector of "Industry" as in 2007/2000 it is minus 5\%, while in the $2016 / 2000$ it is minus $14.3 \%$. This tendency for the two sectors continues in $2016 / 2007$ although with lower rates, as the change is at the expense of increase in employment in the sector of "Services". In a more detailed analysis of the activities that make up the tertiary sector services, a large increase is found out compared to 2000, especially in the sectors "Financial and insurance activities" and "Real estates". Overall, the proportion of people employed in these two sectors is not high, but employment is almost two times greater in the "Real estate"sector. Changes in the primary and secondary sector appear as a prerequisite for the development and climate of the tertiary sector "Services", as variations in employment in this sector are tied to variations of GAV (Gross Added Value) in the same sector and determine the level of relative labour productivity. With the existence of a trend for the increase in the participation of "Services", both in the formation of the GAV and in the participation of employees there are created opportunities for beneficial structural changes associated with higher labour productivity. At the same time, this trend depends on economic conditions and the necessary prerequisites of the economic system to achieve comparative advantages.

Table 1. Structure and dynamics of employees in the Republic of Bulgaria in the sectors of the economy for 2000, 2007 and 2016.

\begin{tabular}{|c|c|c|c|c|c|c|c|c|c|c|c|}
\hline $\begin{array}{l}\text { Structure } \\
\text { and } \\
\text { dynamics } \\
\text { of the } \\
\text { employed }\end{array}$ & Years & 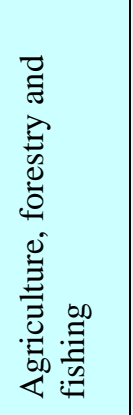 & $\begin{array}{l}\vec{E} \\
\stackrel{\vec{E}}{\Xi} \\
\stackrel{\Xi}{\Xi}\end{array}$ & 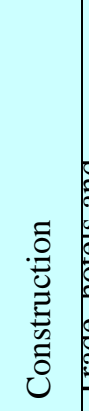 & 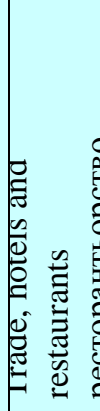 & 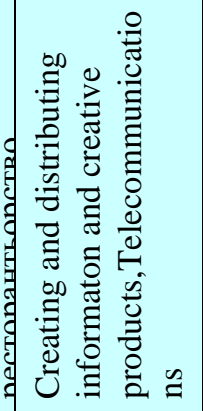 & 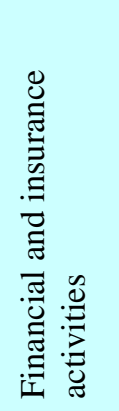 & 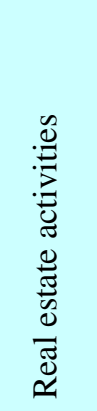 & 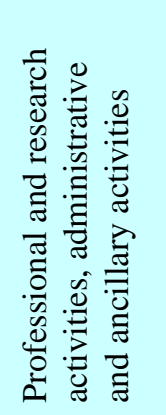 & 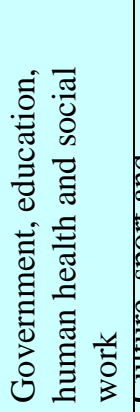 & 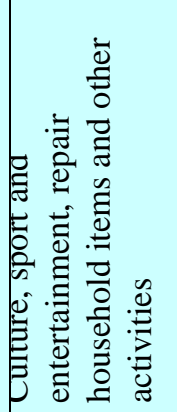 \\
\hline \multirow{3}{*}{$\begin{array}{l}\text { Structure } \\
\text { of } \\
\text { employees } \\
(\%)\end{array}$} & 2000 & 24,1 & 23,6 & 4,2 & 20,4 & 1,6 & 1,1 & 0,4 & 3,8 & 19,0 & 1,8 \\
\hline & 2007 & 19,4 & 22,4 & 6,7 & 23,2 & 1,8 & 1,4 & 0,6 & 5,4 & 16,4 & 2,6 \\
\hline & 2016 & 18,0 & 20,2 & 5,1 & 25,6 & 2,6 & 1,9 & 0,8 & 7,0 & 15,7 & 3,0 \\
\hline \multirow{3}{*}{$\begin{array}{l}\text { Absolute } \\
\text { growth } \\
\text { (percentag } \\
\text { e points) }\end{array}$} & $2007 / 2000$ & $-4,7$ & $-1,2$ & 2,6 & 2,8 & 0,2 & 0,2 & 0,2 & 1,5 & $-2,5$ & 0,8 \\
\hline & $2016 / 2000$ & $-6,0$ & $-3,4$ & 0,9 & 5,2 & 1,0 & 0,7 & 0,4 & 3,2 & $-3,2$ & 1,2 \\
\hline & $2016 / 2007$ & $-1,4$ & $-2,2$ & $-1,7$ & 2,4 & 0,8 & 0,5 & 0,2 & 1,7 & $-0,7$ & 0,5 \\
\hline \multirow{3}{*}{$\begin{array}{l}\text { Growth } \\
\text { rate (\%) }\end{array}$} & $2007 / 2000$ & $-19,4$ & $-5,0$ & 62,3 & 14,0 & 12,2 & 21,1 & 47,8 & 39,7 & $-13,3$ & 44,2 \\
\hline & $2016 / 2000$ & $-25,1$ & 14,3 & 21,9 & 25,6 & 59,3 & 64,6 & 102,2 & 83,3 & $-17,1$ & 69,2 \\
\hline & $2016 / 2007$ & $-7,1$ & $-9,8$ & 24,9 & 10,2 & 42,0 & 35,8 & 36,8 & 31,2 & $-4,4$ & 17,3 \\
\hline
\end{tabular}

Source: NATIONAL STATISTICAL INSTITUTE and author's own calculation (3)

The present study reflects the sectoral structure of employees and its dynamics, as assessed by the intensity of structural changes. This assessment gives a summarized characteristic of the variation and is particularly necessary when structural changes are to be compared and evaluated for two or more periods. The coefficients of structural change and differences calculated over individual periods make it possible to draw conclusions about the strengthening or weakening of the intensity of structural changes in a dynamic aspect. The calculated coefficients of K. Gatev and V. Ryabtsev, characterizing the intensity of structural changes of the employees by sector in 2007 to 2000, are presented in Table 2.

Significant (after the coefficient of K. Gatev and that of V. Ryabtsev) are changes in 2007 compared to 2000 in the primary sector "Agriculture, forestry and fishing ". In the secondary sector, no structural changes are accounted for during this period. Regarding the tertiary sector and its component parts, 
structural changes of significant intensity are specified in the sector, "Financial and insurance activities" which are of significant intensity (according to the coefficient of $\mathrm{K}$. Gatev) and with moderate intensity (according to the coefficient of V. Ryabtsev).
Changes in the structure of the employed in sector "Information and communication"are moderate after Gatev's coefficient and weak after Ryabtsev's coefficient. In the other activities of the tertiary sector structural changes are not recorded or it is a observed weak intensity of the amendments.

Table 2. Integrated coefficients of structural changes by sector in 2007 compared to 2000

\begin{tabular}{|c|c|c|c|}
\hline Sectors & $\begin{array}{l}\text { Integrated } \\
\text { coefficient of } K \text {. } \\
\text { Gatev }\end{array}$ & \begin{tabular}{|l|} 
Ryabtsev's \\
integral coefficient \\
of $\quad$ structural \\
differences \\
\end{tabular} & $\begin{array}{l}\text { Intensity of } \\
\text { structural changes }\end{array}$ \\
\hline Agriculture, forestry and fisheries & $\mathrm{Ks}=0.305$ & $\mathrm{Ksr}=0.221$ & significant \\
\hline Industry (excl. construction) & $\mathrm{Ks}=0.066$ & $\mathrm{Ksr}=0.047$ & $\begin{array}{l}\text { Ks - weak } \\
\text { Ksr - No structural } \\
\text { changes have occurred }\end{array}$ \\
\hline Construction & $\mathrm{Ks}=0.099$ & $\mathrm{Ksr}=0.07$ & weak \\
\hline Trade, transport, hotels and restaurants & $\mathrm{Ks}=0.103$ & $\mathrm{Ksr}=0.073$ & weak \\
\hline Information and communication & $\mathrm{Ks}=0.126$ & $\mathrm{Ksr}=0.089$ & $\begin{array}{l}\text { Ks - moderate } \\
\text { Ksr - weak }\end{array}$ \\
\hline Financial and insurance activities & $\mathrm{Ks}=0.260$ & $\mathrm{Ksr}=0.187$ & $\begin{array}{l}\text { Ks - significant } \\
\text { Ksr - moderate }\end{array}$ \\
\hline Real Estates & $\mathrm{Ks}=0.069$ & $\mathrm{Ksr}=0.045$ & $\begin{array}{l}\text { Ks - weak } \\
\text { Ksr - No structural } \\
\text { changes have occurred } \\
\end{array}$ \\
\hline $\begin{array}{l}\text { Professional activities and scientific } \\
\text { research; Administrative and support } \\
\text { activities }\end{array}$ & $\mathrm{Ks}=0.084$ & $\mathrm{Ksr}=0.059$ & weak \\
\hline $\begin{array}{l}\text { Government, education, health and social } \\
\text { welfare work }\end{array}$ & $\mathrm{Ks}=0.061$ & $\mathrm{Ksr}=0.043$ & weak \\
\hline $\begin{array}{l}\text { Culture, sport and entertainment repair of } \\
\text { household items and other activities }\end{array}$ & $\mathrm{Ks}=0.047$ & $\mathrm{Ksr}=0.033$ & weak \\
\hline
\end{tabular}

Source: NATIONAL STATISTICAL INSTITUTE and author's own calculations (3)

To trace a longer period of time there are calculated Gatev's and Ryabtsev's coefficients, characterizing the intensity of structural changes of employees in 2016 compared to 2000 by sector in comparison to those working in the country. These are presented in the following Table 3.

The results obtained for the period 2000-2016 are not significantly different from those in the period 2000-2007.In 2016 relative to 2000, there are found changes in the structure of employees in the different areas of the country, measured by the integrated coefficient of Gatev and Ryabtsev which are significant in the primary sector of "Agriculture, forestry and fishing ". In the secondary sector changes are of moderate intensity (according to the coefficient of Gatev) and with low intensity (according to the coefficient of Ryabtsev). In a detailed analysis of the tertiary sector it is discovered that the sector "Financial and insurance activities" has significant structural changes over the years from 2016 to 2000 . Gatev's coefficient measures significant intensity of changes in the structure of the monitored period in the "Real estates" sector too, whereas Ryabtsev's coefficient estimates moderate structural changes. This change is the result of reducing the share of the industrial sector at the expense of an increase in the share of the employed mainly in the "Service" industry. Significant structural changes observed versus 2000 that occur in the primary sector, and in some activities of the tertiary sector are due to changes in the structure of the economy associated with the transition of the economic system to market-type relationships. They inevitably influence the greater part of the sectors of the economy. 
STOYCHEVA IV.

Table 3. Integrated coefficients of structural changes in sectors through 2016 compared to 2000

\begin{tabular}{|c|c|c|c|}
\hline Sectors & $\begin{array}{l}\text { Integrated } \\
\text { coefficient of } K \text {. } \\
\text { Gatev }\end{array}$ & $\begin{array}{l}\text { Ryabtsev's integral } \\
\text { coefficient of } \text { structural } \\
\text { differences }\end{array}$ & $\begin{array}{l}\text { Intensity of structural } \\
\text { changes }\end{array}$ \\
\hline Agriculture, forestry and fisheries & $\mathrm{Ks}=0.316$ & $\mathrm{Ksr}=0.229$ & significant \\
\hline Industry (excl. construction) & $\mathrm{Ks}=0.122$ & $\mathrm{Ksr}=0.087$ & $\begin{array}{l}\text { Ks -moderate } \\
\text { Ksr -weak }\end{array}$ \\
\hline Construction & $\mathrm{Ks}=0.118$ & $\mathrm{Ksr}=0.084$ & $\begin{array}{l}\text { Ks - moderate } \\
\text { Ksr - weak }\end{array}$ \\
\hline $\begin{array}{l}\text { Trade, transport, hotels and } \\
\text { restaurants }\end{array}$ & $\mathrm{Ks}=0.090$ & $\mathrm{Ksr}=0.064$ & weak \\
\hline Information and communications & $\mathrm{Ks}=0.548$ & $\mathrm{Ksr}=0.420$ & strong \\
\hline Financial and insurance activities & $\mathrm{Ks}=0.310$ & $\mathrm{Ksr}=0.225$ & significant \\
\hline Real Estates & $\mathrm{Ks}=0.178$ & $\mathrm{Ksr}=0.127$ & moderate \\
\hline $\begin{array}{l}\text { Professional activities and scientific } \\
\text { research; Administrative and } \\
\text { support activities }\end{array}$ & $\mathrm{Ks}=0.130$ & $\mathrm{Ksr}=0.092$ & $\begin{array}{l}\text { Ks - moderate } \\
\text { Ksr - weak }\end{array}$ \\
\hline $\begin{array}{l}\text { Government, education, human } \\
\text { health and social work }\end{array}$ & $\mathrm{Ks}=0.154$ & $\mathrm{Ksr}=0.109$ & $\begin{array}{l}\text { Ks - moderate } \\
\mathrm{Ksr} \text { - weak }\end{array}$ \\
\hline $\begin{array}{l}\text { Culture, sport and entertainment } \\
\text { repair of household items and other } \\
\text { activities }\end{array}$ & $\mathrm{Ks}=0.103$ & $\mathrm{Ksr}=0.073$ & weak \\
\hline
\end{tabular}

Source: NATIONAL STATISTICAL INSTITUTE and author's own calculations (3)

These significant changes in the structure of employment in the primary sector can be explained by the transition of employees from the agricultural sector into the sector of industry and production facilities. The increased share of those employed in services in the period 2000-2007 by 5.9 percentage points is due primarily to a decline of employment in the agricultural sector by 4.7 percentage points. Also, as a whole for the period 2000-2016 years there is a greater mobility of the employed in the primary sector and a smaller one for the secondary sector. The emerging trend of development and expansion of services is related to the development of information and communication technologies and globalization, in which the tertiary sector is the one with higher productivity, due to the low share of employed and the ability to create higher added value.

Employment by sector and the dynamic structural change of participation of employees in one sector or another is influenced by events that have an extremely big influence on the economy of the country, respectively on employment as a whole. These processes are related to:

- completing the transition from a planned economy to a market economy in 2000 and the functioning of the economy in the conditions of the currency board, which provides the country's economic stability.

- the accession of our country to the European Union in 2007, which allows free movement of factors of production such as capital, technology and manpower within a large economy.

- the global economic crisis that resonates more tangibly in our country at the end of 2008 and with time leads to the deterioration of major economic indicators.

In the setting of these and other events, it is reasonable for significant changes to occur concerning the participation of employees in these sectors which foster the development of human capital. To continue the analysis, it also covers the span of 2007-2016, which includes the time after our accession to the European Union and the period of the economic crisis.

The calculated coefficients of Gatev and Ryabtsev, characterizing the intensity of structural changes of employees throughout 2016 compared to 2007 by area are presented in Table 4.

In 2016 compared to 2007 , it is found out that the intensity of the changes in the structure of employees in the different areas of the country is weak in almost all sectors surveyed. The exceptions are three sectors the primary with moderate changes and the tertiary where in the "Information and communications" the coefficient of K. Gatev measures strong intensity of changes in the structure of the observed period, while that of V. Ryabtsev- significant changes. In the sector of "Real estates" the integrated coefficient of $\mathrm{K}$. Gatev shows significant 
intensity, while the index of structural modifications of V. Ryabtsev reflects moderate structural changes. Overall, the sectors in which there have been substantial changes in the structure of employees are: "Agriculture, forestry and fishing"," Information and communications"," "Financial and insurance activities "and"Real estates ". The increased number of employees in the specific activities of the "Services" sector does not guarantee high rates of growth and a higher standard of living. Changes in the structure by sector in Bulgaria are the result of a decline in employment in industry and agriculture which inevitably leads to changes in the structure of the entire economy. The reduction of employment in the agricultural sector would lead to increased labour productivity, if this reduction was at the expense of the overflow of the employed in other sectors. The age structure of employees in agriculture, however, does not imply transfusions in other sectors. That is why regional policy with regard to sectoral employment must be consistent with the socio-economic and demographic parameters of the region. It is also associated with the search of options for displaying the comparative advantages of a sector in the region with a view to developing a more effective structure in employment.

Table 4. Integrated coefficients of structural changes by sector in 2016 compared to 2007

\begin{tabular}{|c|c|c|c|}
\hline Sectors & $\begin{array}{l}\text { Integral } \\
\text { coefficient of } \\
\text { K. Gatev }\end{array}$ & $\begin{array}{c}\text { V. Ryabtsev's } \\
\text { integral coefficient } \\
\text { of structural } \\
\text { differences }\end{array}$ & $\begin{array}{c}\text { Intensity of structural } \\
\text { changes }\end{array}$ \\
\hline Agriculture, forestry and fisheries & $\mathrm{Ks}=0.167$ & $\mathrm{Ksr}=0.119$ & moderate \\
\hline Industry (excl. construction) & $\mathrm{Ks}=0.076$ & $\mathrm{Ksr}=0.053$ & weak \\
\hline Construction & $\mathrm{Ks}=0.067$ & Ksr=0.047 & $\begin{array}{l}\text { Ks -weak } \\
\text { Ksr-very weak }\end{array}$ \\
\hline $\begin{array}{l}\text { Trade, transport, hotels and } \\
\text { restaurants }\end{array}$ & $\mathrm{Ks}=0.046$ & $\mathrm{Ksr}=0.032$ & very weak \\
\hline Information and communication & $\mathrm{Ks}=0.456$ & $\mathrm{Ksr}=0.341$ & $\begin{array}{l}\text { Ks -strong } \\
\text { Ksr-significant }\end{array}$ \\
\hline Financial and insurance activities & $\mathrm{Ks}=0.061$ & $\mathrm{Ksr}=0.043$ & $\begin{array}{l}\text { Ks -weak } \\
\text { Ksr-very weak }\end{array}$ \\
\hline Real estates & $\mathrm{Ks}=0.212$ & Ksr $=0.152$ & $\begin{array}{l}\mathrm{Ks}-\text { significant } \\
\mathrm{Ksr}-\text { moderate }\end{array}$ \\
\hline $\begin{array}{l}\text { Professional activities and } \\
\text { research; Administrative and } \\
\text { ancillary activities }\end{array}$ & $\mathrm{Ks}=0.051$ & Ksr=0.036 & $\begin{array}{l}\text { Ks -weak } \\
\text { Ksr-very weak }\end{array}$ \\
\hline $\begin{array}{l}\text { Government, education, human } \\
\text { health and social work }\end{array}$ & $\mathrm{Ks}=0.099$ & $\mathrm{Ksr}=0.070$ & weak \\
\hline $\begin{array}{l}\text { Culture, sport and entertainment } \\
\text { repair of household items and } \\
\text { other activities }\end{array}$ & $\mathrm{Ks}=0.109$ & $\mathrm{Ksr}=0.077$ & weak \\
\hline
\end{tabular}

Source: NATIONAL STATISTICAL INSTITUTE and author's own calculations (3)

\section{CONCLUSION}

In spite of the reduction in the share of employment in the primary sector of agriculture and in the secondary sector of industry and the increase of employment in the service sector for the period 2000-2016, the sectoral restructuring processes in the country will continue as significant fluctuations in employment on key sectors and areas. The sectoral structure of employment is one of the leading factors that forms regional differences and determines the level of socio-economic development of the regions. The high share of employment in the primary sector is associated with low levels of GVA and GDP per capita, with lower relative labour productivity, respectively with a lower rate of economic growth, while the high percentage of employment in the sector "Industry" is 
associated with a higher level of economic development. The development of the "Services" sector is a result of the level of employment in the agricultural sector, as well as of the participation of employees in the "Industry "sector and these changes result in an overflow of resources from sectors with low to sectors with high labour productivity. The opportunities for economic development of the country as a whole are related to the level of industrialization, yet there tend to be favourable structural changes in services. This can be achieved through in-depth analysis of the structural changes in the sector, with a view to establishing these activities and areas for which our country may have comparative advantages and which can provide higher efficiency or economic growth. Moreover, with the achievement of structural changes in the direction of the development of certain activities in the field of the services does not require high investments.

\section{REFERENCES}

1. Gatev, K., Methods of analysis of structures and structural effects, S., Holding, 2007

2. Todorov, T., Structural changes in the Bulgarian Economy (1980-2008), Svishtov, Dialogue, 2010, p. 19-35

3. http://www.nsi.bg/

4. Yankova, N., Statistical survey of structura 1 changes, Sofia, AI"Prof. Marin Drinov, 2007.

5. Totev, S., Economic integration and conve rgence of EU countries, A

study in the journal "Economic Thought", vol. 5, p. 1. 3-23, 2010. 